So far as we can see from the discussion of Mr. Davies, the point which he wishes to emphasize is that the ideal is a functional transcendent unit, based upon individual experience and differing from such experience. But his interpretation of Baldwin's theory of imitation seems somewhat askew. This, however, by no means interferes with the excellence of his treatment, as such.

Felix Arnold.

NEW YORK CITY.

\title{
CODE OF HONOR.
}

The College Woman's Code of Honor. Amy E. Tanner. Ped. Sem., 1906, XIII., Pp. I04-1 I7.

A number of questions regarding what the answerer would do in various situations that are likely to occur and involving petty temptations and fine moral discrimination were given to the young women of several women's colleges and co-educational colleges. The answers from $44^{\circ}$ students indicate that one half would condemn keeping carfare uncalled for, using a 'pony,' using a point accidentally seen on another's paper during an examination, and telling stories to a credulous girl, while the rest would defend such action or decide variously according to the exact circumstances of the case. There is little condemnation of 'bluffing' in recitations, telling white lies, exaggerating, or the acceptance of unduly favorable opinions of self. The college girl has a thoroughgoing contempt for sneaking and out and out lying, but with sufficient intelligence and sense of humor in most cases to enjoy any sort of contest with wits even though she risks her scholarly reputation.

Socially she is on the whole warm hearted enough to sacrifice the truth in small matters to the demands of friendship and courtesy, but rarely has she sufficient social sense to undertake the punishment of a wrong doer. The author emphasizes the need of more democracy and self government in school and college. E. A. KIRKPATrick.

State NoRMaI SCHOOL,

Firchburg, Mass.

\section{BOOKS RECEIVED FROM FEBRUARY 5 TO MARCH 5 .}

Textbook of Psychiatry. E. Mendel. Trans, by W. C. Krauss. Philadelphia, Davis Co., 1907. Pp. xiv + 31 I.

The Psychology of Public Speaking. W. D. Scotr. Pearson Bros. (No place or date.) Pp. 222. 